\title{
LA INVESTIGACIÓN DE W. M. GABB EN TALAMANCA Y LA SITUACIÓN CARTOGRÁFICA EN COSTA RICA, AÑO 1877
}

\author{
Augusto Petermann \\ Alemania \\ Traducción del alemán original por Siegfried Kussmaul, \\ Escuela Centroamericana de Geología, Universidad de Costa Rica \\ Documento original tomado de Mitteilungen aus \\ Justus Pethes' Geographischer, Gotha 23(10), págs. 385-387
}

En el volumen correspondiente al año 1869, ofrecimos una revisión de la situación geográficacartográfica de Costa Rica y una lista de la literatura referente al desarrollo de los conocimientos de este país desde el año 1502 hasta $1869^{1}$. En esta ocasión se mencionó que la exploración de esta región, en los 400 años siguientes al descubrimiento, era sumamente lenta y que la suma de los conocimientos actuales es muy escasa e incompleta para un estado de buena cultura y con una política ordenada. Mapas más o menos exactos, basados en mediciones aparecieron apenas en los años 1794 y 1836 gracias a las representaciones de la costa, realizada por Bauza y del interior del país por Galindo, seguido por el mapa de J. Baily en 1850, mientras que el mapa de Max Sonnenstern de 1860 más bien representa un enorme retroceso.
Así eran las cosas cuando en aquella época editamos un mapa nuevo ${ }^{2}$, en el cual recopilamos todo lo referente al conocimiento del país hasta el año 1869. En este tiempo solamente existían tres levantamientos más o menos exactos de: las ubicaciones de la costa en el este y el oeste y una sola travesía a través del país, desde Puerto Limón, pasando por Cartago y San José hasta Punta Arenas [sic]; además existían unos pocos cerros, cuya ubicación fue determinada desde el mar. El cartografiado del país se basó principalmente en exploraciones inexactas y solamente una pequeña parte se debe a mediciones provisionales y reconocimientos deficientes. Un levantamiento completo, como se acostumbra en los países europeos, no existe de ninguna parte del país, tampoco porque no había ninguna necesidad por parte de los intereses locales; el número de habitantes

PETERMANN, A., 1877: La investigación de W. M. Gabb en Talamanca y la situación cartográfica en Costa Rica, año 1877.Traducción de KUSSMAUL, S., 2007 [del original publicado en Mitteilungen aus Justus Pethes' Geographischer, Gotha 23(10):385-387].- Rev. Geol. Amér. Central, 37 Especial: 119-122. 
todavía es sumamente pequeño y las áreas cultivadas son muy limitadas. De los 185000 habitantes, que se supone viven en todo el estado, 7/8 habitan probablemente en las cercanías de la capital, principalmente entre Cartago y Alajuela, o en sentido más amplio, entre Angostura y Punta Arenas [sic]; en el resto del país viven tal vez solo unas 10 personas por milla cuadrada. Una selva impenetrable cubre gran parte y el carácter general es de un país montañoso con crestas empinadas y angostas y ríos montañosos rápidos. De los 1011 millas cuadradas que se supone cubre todo el país, solamente unos 55 , o sea $1 / 20$, son cultivadas [NT"1].

El primer levantamiento de un área más o menos grande y continuo de Costa Rica, la región de la cordillera de Talamanca, en el sureste del país, lo realizó el profesor William M. Gabb en los años 1873 y 1874, el geólogo e investigador estadounidense, bien conocido y de mucho prestigio. De sus trabajos anteriores esta misma revista publicó algunos ${ }^{3}$. Este levantamiento se extiende desde la costa entre Puerto Limón y Punta Sorobeta hasta llegar a la cordillera de Talamanca y abarca principalmente las cuencas del río Tiliri y del río Tilorio. Causó un cambio fundamental de nuestros conocimientos de la parte sur de Costa Rica como se puede ver fácilmente, comparando nuestro mapa nuevo (Lámina 18) con el anterior, publicado en la Lámina 5 del Volumen $1869^{4}$.

Tenemos el levantamiento de la parte sureste de Costa Rica desde casi tres años, pero como creímos que el gobierno del país lo divulgaría, no nos apuramos en publicarlo. Sin embargo, como en los últimos años se publicaron mapas grandes y pretenciosos con apariencia oficial, donde no se incluyeron estos levantamientos, que son los más importantes que se realizaron hasta la fecha en Costa Rica, decidimos incluirlo en la Lámina 18 del presente volumen.

El Profesor Wm. M. Gabb nos escribió el 30 de noviembre de 1874 una carta desde San José, Costa Rica, en la cual dice entre otras cosas: "Con excepción de la faja costera cerca de Puerto Limón, todo el mapa se basa en nuestros propios levantamientos. Esta franja costera se tomó de un levantamiento de Beyer y, siguiendo el deseo del Ministro de Obras
Públicas se incluyó en nuestro mapa. No solamente realizamos un levantamiento en el interior del país, sino también hicimos un levantamiento nuevo y exacto de la costa entre Puerto Limón y Boca del Drago, basándonos en una combinación de cadena de medición y triangulación ${ }^{5}$.

"A pesar de que todo el país está cubierto por selva virgen, con excepción de las áreas deforestadas para la agricultura, medimos desde Limón, Cajuita [sic] y también otros puntos los ángulos de las cimas de las montañas y de los cerros más altos medimos unos triángulos grandes, de manera que pudimos determinar con una exactitud aceptable las características topográficas principales del país. Con uno de mis ayudantes determiné con bastante exactitud la topografía del área del Tilorio y de los afluentes orientales del Tiliri y posteriormente, durante varias campañas en el curso de más de un año investigué las regiones del Lari, Coen y Tiliri, con la limitación que me puso la naturaleza del país."

"La exactitud de los levantamientos debe ser mayor que en muchos países civilizados. La ubicación de todos los ríos es buena, su extensión fue determinada con mucha exactitud, la nomenclatura se basa en la fonética, utilizando el alfabeto español. Encontrará que cambié algunos nombres. Los términos Changinola ${ }^{6}$ y Sicsaula (o Sicsola) vienen del mosquito y solamente son utilizados por los negros en la costa y de las personas que los adoptaron de estos. Sin embargo, los nombres verdaderos de estos ríos son Tilorio y Tiliri, porque solamente con estos nombres son llamados por los habitantes de la región, los indios. Sicsola, en el idioma mosquito, significa río de banano $($ ola $=$ río $)$, también cerca de Limón existe un río Banana y un río Bananita y otro que desemboca en la laguna Chiriquí. Changinola, el río de los indios Changina, solamente se refiere al brazo en cuya ribera vivieron; al lado del río principal solamente habitan los Tiribis y estos llaman al río exclusivamente Tilorio. Teliriñak, que aparece en su mapa (1869) es una corrupción de las palabras en Bribri "Tiliri nyak" que significa "desembocadura del Tiliri"."

"Toda la región está cubierta por bosque, las montañas son escarpadas y las crestas casi siempre muy estrechas, por lo tanto, los ríos tienen 
muchos saltos y son muy caudalosos. El delta del Tiliri y alrededores está formado por una planicie aluvial ondulada, muy apta para la siembra de caña dulce. Durante todas las épocas del año el Tiliri es navegable con botes grandes hasta Suretka y siguiendo el Urén hasta Sipurio; la barra en la desembocadura del río solamente es un peligro durante dos meses por año. La parte superior del río Tiliri, como también del río Coen, está formada por numerosos brazos e islas, que están expuestos a cambios frecuentes, ya que en el caso de lluvias tropicales fuertes hay inundaciones y antiguos brazos e islas desaparecen y se forman nuevos. En un sitio encontré el río Tiliri con un ancho de una milla. El Lari y Urén ${ }^{7}$ no se comportan igual porque el fondo del valle de estos ríos es menos ancho. Lo mismo vale para la parte inferior del río principal."

"Con toda seguridad, el Tilorio es navegable hasta Bunzhik, de ahí en adelante, en un viaje con muchas dificultades, se puede llegar en bote hasta Schungso, pero más arriba no. Dicen que la naciente más alejada del Tilorio es un lago pequeño en la cima de un cerro, posiblemente un cráter extinto."

"De acuerdo con descripciones anteriores se pensó que el Pico Blanco o Kamuk, como lo llaman los indios, no está situada en la cordillera principal, pero esto no es correcto. Las fuentes del Lari y Urén, determiné con mucha exactitud, todas las aguas del lado opuesto de la cordillera corren directamente hacia el Océano Grande. Pico Blanco está situado exactamente en la cresta y no alejada de esta. U-jum, el cerro desnudo en el idioma de los indios, donde nace el Coen, también está ubicado en la cresta, pero el U-jum de Bribri, que llamé Lyon, porque no tenía un nombre específico, está situada un poco fuera de la cresta, entre las nacientes del Lari y del Dipari. La altura de estos dos cerros la medí aproximadamente desde las faldas del Pico Blanco, nivelando a partir de una altura con determinación barométrica."

"Con respecto a la población, encargué un censo en la región donde hicimos el levantamiento cartográfico y resultó que habitan 1226 indios y 12 extranjeros ${ }^{8}$, de los últimos solamente uno es americano, los otros 11 son mulatos y mestizos."

\section{Notas}

${ }^{1}$ Dr. A. v. Frantzius, der geographische Standpunkt von Costa Rica [La posición geográfica-cartográfica de Costa Rica] (Geogr.- Mitth. 1869, p. 81-84 + Lámina 5).

${ }^{2}$ Lámina 5, Geogr.- Mitth. 1869.

${ }^{3}$ Por ejemplo la exploración y el levantamiento en el interior de la península de California (Geogr. Mitth. 1868, p. 273 y lámina 14), el levantamiento de la parte oriental de la isla de Haití (Geogr. Mitth. 1874, p. 321 y lámina 17).

${ }^{4} \mathrm{O}$ el mapa publicado por Friederichsen, Hamburgo, en el año 1876. Este mapa, en general, es similar al nuestro del 1869. Solo de vez en cuando hay algunas diferencias en los detalles, por ejemplo, en el trayecto Limón - Punta Arenas [sic], una traza que en forma general ya indicó $\mathrm{F}$. Kurtze, C.E. Director General de Obras Públicas de la República de Costa Rica, y que publicó en el año 1866 en su obra "The Intraoceanic Railroad Route through the Republic of Costa-Rica". Solamente en una zona este mapa es completamente diferente del nuestro de 1869 , específicamente en la zona de Talamanca, y por eso es un retroceso, porque incluye los levantamientos antiguos y erróneos de Wagner, Codazzi y Obaldia; así por ejemplo, dejan desembocar el río grande de Tiliri en el riachuelo Hone, cerca de Puerto Viejo, en la desembocadura del Tiliri o Sicsola colocan un río imaginario Tervis, el Sicsola dejan desembocar al mar cerca de la laguna Sansan, etc. Estas confusiones ya fueron corregidos en nuestro mapa de 1869 , cuyo diseño se basó para el interior del país casi exclusivamente en las comunicaciones de Valentini quien estuvo durante unos meses en Limón y sus datos se basan solamente en noticias recibidas, sin mediciones ni conocimientos del interior.

${ }^{5}$ Por este motivo difiere enormemente del anterior levantamiento inglés de la costa. Parece que justo en esta zona este levantamiento era muy rápido, ya que en todo el trecho entre Limón y Bocas del Toro ni un solo punto fue determinado astronómicamente, lo mismo indica también Raper.

${ }^{6}$ Por un error, en algunos ejemplares quedó el nombre de Changuinola en lugar de Changinola. 
${ }^{7}$ Por un error, en algunos ejemplares falta el nombre del río Urén; es el río que pasa cerca de Sipuro y atraviesa la región de los indios Urén.

${ }^{8}$ De acuerdo con nuestros cálculos, el área levantado por Gabb comprende aproximadamente 120 millas alemanas cuadradas [unos $4915 \mathrm{~km}^{2}$ ], o sea, abarca más o menos la misma área del Ducado de Oldenburgo.
NT1: Nota del traductor: Una milla alemana equivale a la decimoquinta parte de un grado, y por lo tanto, 4 millas náuticas, o bien $6,4 \mathrm{~km}$. De tal manera, una milla cuadrada son $40,96 \mathrm{~km}^{2}$, y el cálculo de 1011 millas cuadradas viene a ser 41 $411 \mathrm{~km}^{2}$, en realidad un $81 \%$ del territorio real actual. Debe tomarse en cuenta sin embargo, que en ese tiempo Costa Rica era más grande, puesto que parte del actual territorio panameño era costarricense, y por lo tanto, la subestimación es mayor. 